Original Research Article

\title{
Assessment of drug related problems and clinical pharmacist interventions in paediatric department of a tertiary care teaching hospital
}

\author{
Deepishka Pemmasani*, Sai Deepak Gali, Maanasa Arcot, Durga Prasad T. S.
}

\begin{abstract}
Department of Pharmacy
Practice, Sri Padmavathi School of Pharmacy, Jawaharlal Nehru Technological University, Anantapuramu, Andhra Pradesh, India
\end{abstract}

Received: 16 July 2018

Accepted: 11 August 2018

\section{*Correspondence to: \\ Deepishka Pemmasani, Email: deepishkapemmasanispsp @gmail.com}

Copyright: () the author(s), publisher and licensee Medip Academy. This is an openaccess article distributed under the terms of the Creative Commons Attribution NonCommercial License, which permits unrestricted noncommercial use, distribution, and reproduction in any medium, provided the original work is properly cited.

\begin{abstract}
Background: Drug-related problems (DRPs) are frequent in hospitalization in pediatrics. The main aim of present investigation is to assess drug related problems and clinical pharmacist interventions in pediatric department of tertiary care hospital.

Methods: It was a prospective, observational and interventional study carried over a period of 6 months.

Results: A total of 66 patients were identified with drug related problems. Among them $31(42 \%)$ were in between 1month-2 years followed by $25(34 \%)$ were in between 2-11 years, $10(24 \%)$ were in between 11-18 years of age. $30(45.3 \%)$ patients were prescribed with $0-3$ drugs followed by $21(31.3 \%)$ were prescribed with 3-5 drugs, 15(23.3\%) were prescribed with 6-10 drugs. Most of the DRP's observed in the study were drug interactions 52(78.78\%) [major-19 $(36.53 \%)$, moderate-27 $(5192 \%)$ and minor-6(11.53\%)] followed by adverse drug reactions $12(18.18 \%)$, and duplication errors were $2(3.03 \%)$. Majority of the clinical pharmacist recommendations were duration change $52(34.66 \%)$, drug change $10(6.66 \%)$, dose reduction $2(1.35 \%)$ followed by drug termination $2(1.33 \%)$. Major significance of DRPs were noted high 31(57.96\%), whereas 25 $(39.8 \%)$ were moderate and $8(12.12 \%)$ were minor. The acceptance rate of intervening clinical pharmacist recommendation and change in drug therapy was found to be high in $57(86.66 \%)$ cases while in $9(13.33 \%)$ cases suggestions were accepted but therapy was not changed. There were no cases with neither suggestion were accepted nor therapy changed.

Conclusions: Clinical pharmacist involvement in inpatient pediatric care can significantly help to identify, resolve and prevent the drug related problems. The study concluded that the clinical pharmacist has a significant role in patients care at hospital.
\end{abstract}

Keywords: Clinical pharmacist, Drug therapy, Drug related Problems (DRPs), Intervention, Paediatrics

\section{INTRODUCTION}

Paediatrics is a branch of medicine dealing with the development, diseases, and disorders of children. Paediatrics, unlike the other subjects includes a wide spectrum of age groups. The International Committee of Harmonization (2000) has suggested the classification as: Preterm newborn infants, Term newborn infants (0-27 days), infants and toddlers (28 days- 23 months), children (2-11 years), Adolescents (12-16/18 years). Each of these age groups have their own physiological, pharmacological, pathological and therapeutic characteristics which need to be remembered while handling respective age groups in clinical situations. ${ }^{1}$

The paediatric group of population is a risky population to be affected easily by DRPs, as pharmacodynamics and pharmacokinetic behaviour of drugs in this population usually is different than adults. ${ }^{2}$ Paediatrics possesses a unique set of risks predominantly due to wide variation in 
physical and pharmacokinetic parameters so it requires appropriate medication regimen, administration and pharmaceutical care which are included in clinical pharmacist intervention. ${ }^{3}$

A Clinical pharmacist intervention is defined as "any action by a clinical pharmacist that directly results in a change in patient management or therapy to prevent a drug related problem". ${ }^{4}$ A drug-related problem (DRP) is defined as 'an event or circumstance involving drug therapy that actually or potentially interferes with desired health outcomes. An actual problem has resulted in clinical manifestations like adverse drug reaction or therapy failure due to incorrect dosage. A potential problem is not manifest, but if left unresolved, it may lead to drug-related harm to the patient. ${ }^{5}$

Drug-related problems are frequent in hospitalization where multiple changes in patient's medication regimens and lack of continuity of care may be accompanied. They may leads to reduced quality of life, increase hospital stay, overall increase health cost and even increase risk of morbidity and mortality. ${ }^{6-8}$ Studies have shown that majority of Drug-related problems (50-80\%) are often preventable, and pharmaceutical services can reduce the number of ADRs, the length of hospital stays, and the cost of care. ${ }^{5}$

It makes challenges for physician during the prescribing of medicines as per the disease of the paediatric patients. Clinical pharmacist intervention will help in improving therapeutic outcome and quality of care. ${ }^{9}$ Though the prevention of DRP is responsibility of every health care professional, the clinical pharmacist can play better role in preventing DRP's as they are involved in each step of medication utilisation process in a hospital.

Hence this study was carried out to assess various drug related problems and clinical pharmacist interventions in the provision of therapy to the paediatrics inpatients.

\section{METHODS}

It is a prospective, observational and interventional study conducted for six months (August 2017 to January 2018) at inpatient department of Paediatrics, Sri Venkateshwara Ramnarayana Ruia Government General Hospital, a 1200 bedded tertiary care teaching hospital in Tirupathi.

\section{Inclusion criteria}

All inpatients of either gender of any age group of paediatrics undergoing treatment in the inpatient paediatric wards of the hospital were included in the study.

\section{Exclusion criteria}

Patients undergoing treatment less than three days of hospital stay were excluded.

\section{Study materials}

Data was collected from inpatients case sheets (case records, medication chart and laboratory reports etc) and screened for any drug related problems.

The working principle consists of patient's data collection, pharmaceutical care evaluation and participation in ward rounds.

All the prescriptions which contain different drugs were included in the study. The prescriptions were analysed for the drug related problems and medication errors. Based on the severity and the nature of drug related problems and medication errors identified, they were brought to the notice of concerned physician or nursing staff or other health care professional by clinical pharmacist to take necessary action.

The acceptance level of physician for the particular intervention, whether there was a change in therapy or not was noted and recorded in clinical pharmacist intervention form, which was suitably designed for the study.

\section{Statistical analysis}

The collected data was analysed using Microsoft excel 2016. The results were proposed in average, number and percentage.

\section{RESULTS}

A total of 150 patients were followed, out of them 66 patients were identified with at least one drug related problem. Among all the age groups affected by drug related problems, patients belonging to the age group of $1 \mathrm{M}-2 \mathrm{Y}$ $(47 \%)$ were high followed by $2 \mathrm{Y}-11 \mathrm{Y}(38 \%)$ and $11 \mathrm{Y}-18 \mathrm{Y}$ (15\%) (Figure 1).

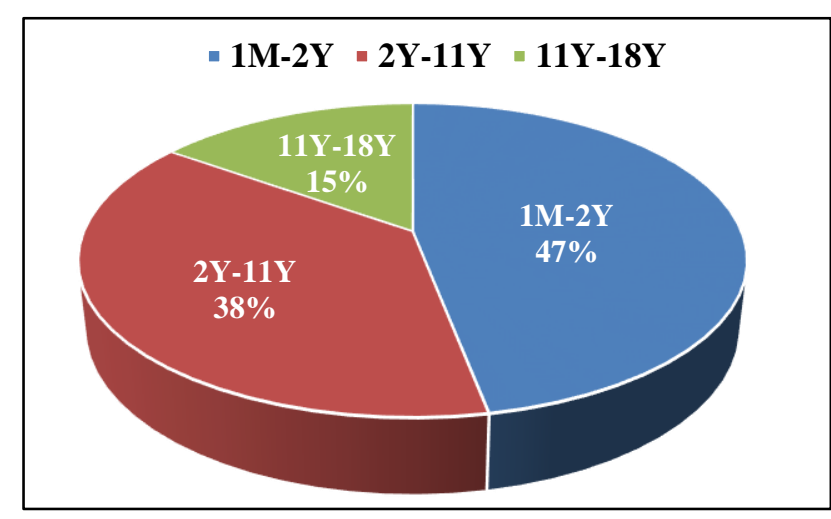

Figure 1: Age wise distribution of the patients identified with drug related problems.

Male patients $84(57.6 \%)$ were more susceptible than female patients $66(45.6 \%)$ (Figure 2). The number of drugs prescribed per patients during the hospital stay was analysed. 
The patients taking 0-3 drugs $(45.3 \%)$ were most common when compared with patients taking 3-5 drugs (31.3\%) and 5-10 drugs (23.3\%) (Table 1).

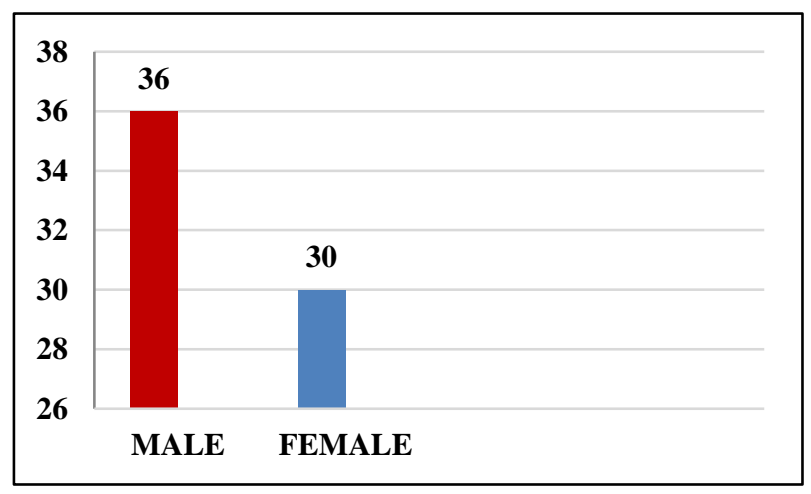

Figure 2: Gender wise distribution of the patients identified with drug related problems.

Table 1: Number of drugs per prescription of patients identified with drug related problems.

\begin{tabular}{|lll|}
\hline $\begin{array}{l}\text { Number of drugs } \\
\text { per prescription }\end{array}$ & $\begin{array}{l}\text { Number of } \\
\text { Patients }\end{array}$ & $\begin{array}{l}\text { Percent } \\
(\%)\end{array}$ \\
\hline $0-3$ & 30 & 45.3 \\
\hline $3-5$ & 21 & 31.3 \\
\hline $5-10$ & 15 & 23.3 \\
\hline
\end{tabular}

Table 2: Therapeutic class wise distribution of the drugs prescribed for the patients identified with drug related problems.

\begin{tabular}{|lll|}
\hline Therapeutic class & No. of drugs & Percent (\%) \\
\hline Antipyretic & 52 & 20.9 \\
\hline Antiepileptic & 16 & 6.5 \\
\hline Antibiotic & 72 & 29.1 \\
\hline Antiulcer & 18 & 7.12 \\
\hline Analgesic & 12 & 4.68 \\
\hline $\begin{array}{l}\text { Vitamin } \\
\text { supplements }\end{array}$ & 17 & 6.72 \\
\hline Antihistamines & 12 & 4.8 \\
\hline Antiemetic & 10 & 4.07 \\
\hline Bronchodilators & 9 & 3.66 \\
\hline Corticosteroids & 6 & 2.24 \\
\hline Laxatives & 2 & 0.61 \\
\hline Cardiac glycosides & 2 & 0.81 \\
\hline Antitubercular & 6 & 2.44 \\
\hline Diuretics & 2 & 0.81 \\
\hline Antivirals & 2 & 0.61 \\
\hline Antiplatelets & 1 & 0.40 \\
\hline
\end{tabular}

Therapeutic class wise distribution of drugs prescribed for patients with drug related problems was analysed. Among them, 143 drugs were antibiotics, 103 were antipyretics, 35 were anti ulcers, 32 were anti emetics, 24 were antihistamines, 23 were analgesics, 20 were antiepileptics, 18 were bronchodilators, 12 were anti tubercular drugs, 11 were corticosteroids, 4 were laxatives, 4 were diuretics, 3 were antiviral and 2 were anti platelets (Table 2).

Among the 150 patients followed up in this study, 66 (44\%) patients were identified with drug related problems among them, $52(78.78 \%)$ patients were identified with drug interactions, $12(18.18 \%)$ patients were identified with adverse drug reactions and $2(3.03 \%)$ patients were identified with duplication errors (Figure 3 ).

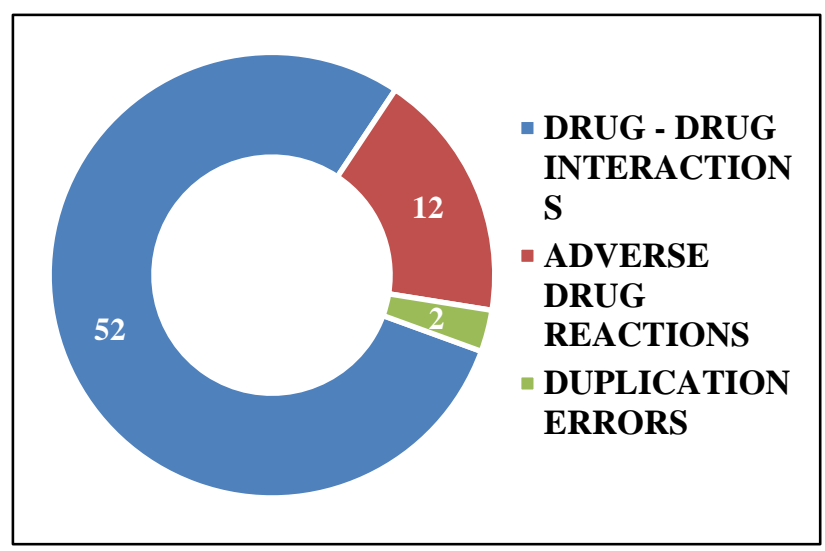

Figure 3: Drug related problems identified in the patients.

Among the drug interactions19 $(36.53 \%)$ were major interactions, $27(51.92 \%)$ were moderate and $6(11.53 \%)$ were minor. Following the drug interactions, there are 12 $(18.18 \%)$ adverse reactions and $2(3.03 \%)$ were duplication errors (Table 3).

Table 3: Types of drug related problems identified.

\begin{tabular}{|lll|}
\hline $\begin{array}{l}\text { Type of drug } \\
\text { related problem }\end{array}$ & $\begin{array}{l}\text { Number of drug } \\
\text { related problems }\end{array}$ & $\begin{array}{l}\text { Percent } \\
(\%)\end{array}$ \\
\hline Drug interactions & & 36.53 \\
\hline Major & 19 & 51.92 \\
\hline Moderate & 27 & 11.53 \\
\hline Minor & 6 & 18.18 \\
\hline $\begin{array}{l}\text { Adverse drug } \\
\text { reactions }\end{array}$ & 12 & 3.03 \\
\hline Duplication errors & 2 & \\
\hline
\end{tabular}

Severity of drug related problems was determined. Out of 66 drug related problems identified, $8(5.33 \%)$ were rated as minor, 27 (74\%) were rated as moderate and $31(20.6 \%)$ were rated as major (Figure 4).

The Pharmacist recommendations to the physicians during the study was analysed. The recommendation most done was duration change in 52 (34\%) prescriptions, drug change in $10(6 \%)$ prescriptions, and dose reduction and change in drug termination in $1(2 \%)$ prescription (Figure 5). Among 66 recommendations, 57 (86.6\%) recommendations were accepted and therapy was changed. However, in $9(13.33 \%)$ of total recommendations, the 
suggestions made by the clinical pharmacist was accepted but the therapy was not changed (Table 4).

Out of 66 interventions, interventions provided to nurse were $19(30 \%)$, to care taker were $32(48 \%)$ and to physicians were 14 (22\%) (Table 5).

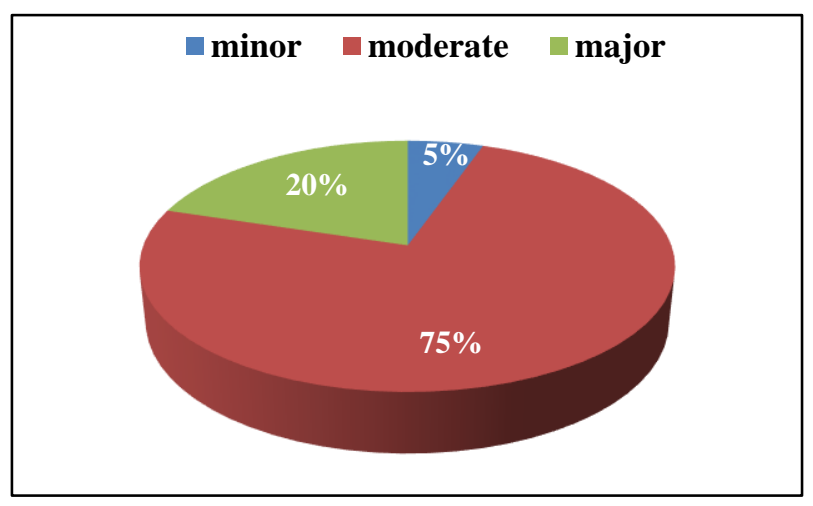

Figure 4: Significance level of drug related problems identified.

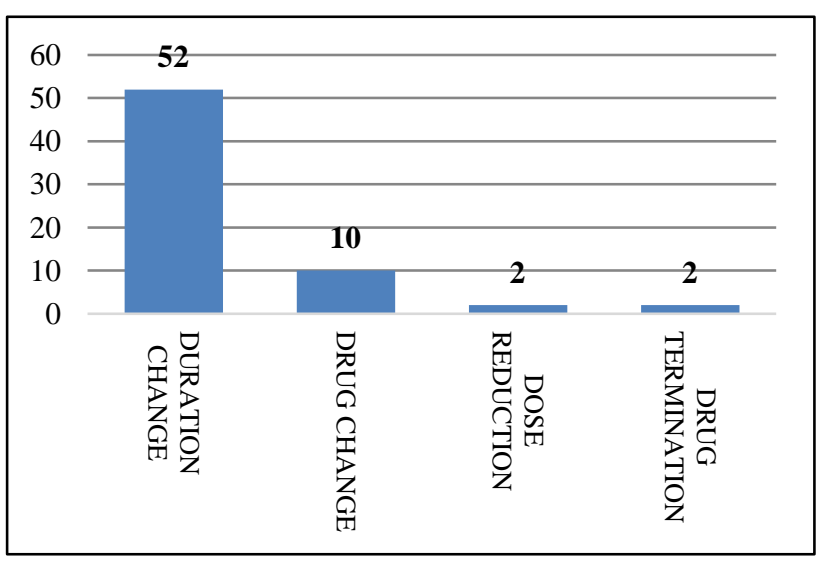

Figure 5: Types of recommendations provided

Table 4: Result of interventions.

\begin{tabular}{|l|l|l|}
\hline Results of interventions & $\begin{array}{l}\text { No. of } \\
\text { cases }\end{array}$ & $\begin{array}{l}\text { Percent } \\
(\%)\end{array}$ \\
\hline $\begin{array}{l}\text { Neither suggestion accepted, } \\
\text { nor therapy changed }\end{array}$ & 0 & 0 \\
\hline $\begin{array}{l}\text { Suggestion accepted but } \\
\text { therapy not changed }\end{array}$ & 9 & 13.33 \\
\hline $\begin{array}{l}\text { Suggestion accepted, and } \\
\text { therapy changed }\end{array}$ & 57 & 86.66 \\
\hline
\end{tabular}

\section{DISCUSSION}

Clinical pharmacy services in hospital are not a novel concept but in the context of India, it is a recently emerging discipline. Even though drug related problems and medication errors are common in all departments, paediatrics is the vulnerable population who are susceptible and sensitive to the drug related problems and due to their underdeveloped physiological conditions and unavailability of accurate doses and dosage forms. With the view of expanded roles and services of the clinical pharmacist in providing improved patient care in hospitalized paediatric patients, we carried out this study and assessed the clinical pharmacist-initiated changes in patient's drug therapy and prevention of drug related problems in paediatric inpatients of tertiary care teaching hospital. Prescriptions of 150 consecutive paediatric admissions were audited and 66 patients were identified with Drug related problems.

Table 5: Interventions provided to various health care professionals and patient care takers.

\begin{tabular}{|ll|}
\hline Interventions & Provided to \\
\hline Duration change & Nurse (19) \\
\hline Major drug & Patient care taker (27) \\
\hline Moderate drug interactions & Patient care taker (6) \\
\hline Minor drug interactions & Physicians (10) \\
\hline $\begin{array}{l}\text { Drug change - Adverse drug } \\
\text { reactions }\end{array}$ & Physicians (2) \\
\hline $\begin{array}{l}\text { Dose reduction- Adverse drug } \\
\text { reactions }\end{array}$ & Physician (2) \\
\hline $\begin{array}{l}\text { Drug termination -Duplication } \\
\text { errors }\end{array}$ & \\
\hline
\end{tabular}

Among the study population, 66 patients were identified with drug related problems. Their demographic details revealed that the incidence of drug related problems were higher in males $(56.6 \%)$ followed by females $(43.3 \%)$ which is similar when compared to the study conducted by Kumar SBP et al. ${ }^{10}$ Among all the age groups affected by drug related problems and medication errors, patients belonging to the age group of $1 \mathrm{M}-2 \mathrm{Y}(42 \%)$ were higher as compared to Jose et al, followed by $2 \mathrm{Y}-11 \mathrm{Y}(34 \%)$ and $11 \mathrm{Y}-18 \mathrm{Y}(24 \%) .{ }^{11}$ The number of drugs prescribed per patient with drug related problems and medication errors during the hospital stay was analysed. The patients taking 0-3 drugs (45.3\%) were most common when compared with patients taking drugs 3-5 (31.3\%) and 5-10 (23.3\%).

The prescribing patterns of drugs in this study population of intervened patients were analysed. The most common group of drugs prescribed was antibiotics $(29.31 \%)$ which is similar to the study conducted By jose et al, and then antipyretics $(20.9 \%)$ anti-ulcers $(7.12 \%)$, vitamin supplements $(6.72 \%)$ antiepileptics $(6.5 \%)$, analgesics $(4.68 \%)$, anti-emetics $(4.07 \%)$, antihistamines $(4.8 \%)$, bronchodilators $(3.66 \%)$, antitubercular drugs $(2.44 \%)$, corticosteroids $(2.24 \%)$ and others. ${ }^{11}$

The most common group of prescribed drugs were antibiotics which has become a routine practice for treatment of pediatric illness. These agents are prescribed for the treatment of critical illness and for prevention of infections in critically ill patients especially in pediatrics who are having under development stage of immunity, increased susceptibility to virulent microorganisms as well 
as during different medical procedures or use of medical devices.

The second most common group of drugs prescribed was antipyretics for treatment of fever which is the most common findings as the sign of infections during presentation to hospital.

The next most common group is anti-ulcers for the prevention of development of ulcers in stomach due to administration of gastric irritant drugs followed by antiepileptics for seizure disorders, analgesics to relieve pain and others drugs were prescribed for their respective indications like bronchodilators for lower respiratory tract infections and asthma, anti-tubercular drugs for tubercular meningitis and pulmonary tuberculosis, corticosteroids in cases like nephrotic syndrome and utricaria, cardiac glycosides for Ventricular Septal Defect (VSD) and congenital heart diseases. Diuretics for kidney diseases like acute glomerulo-nephritis etc. Among vitamin supplements the common prescribed were vitamin A, vitamin $\mathrm{D}$, vitamin $\mathrm{K}$, iron, foilc acid and calcium for deficiency disorders and nutrition related disorders like SAM, and anemia.

Among the 150 patients followed up in this study, 66 (44\%) drug related problems were identified. They were drug interactions, adverse drug reactions and duplication errors. Among them 52 (78.78\%) were drug interactions of which $19(36.53 \%)$ were major interactions, 27 (51.92\%) were moderate and $6(11.53 \%)$ were minor. Following the drug interactions, there are $12(18.18 \%)$ adverse reactions and 2 $(3.03 \%)$ were duplication errors.

Drug interactions were the first most common type of drug related problem $(10 \%)$ which is similar to the study done by Jose et al (71\%) which includes major drug interaction, moderate drug interaction and minor drug interaction based on its effect on therapy of patient. ${ }^{11}$ The percentage of potential Drug-Drug interactions in the paediatric ward is probably related to prevalence of infectious diseases and lack of physician knowledge about drug pharmacokinetics and pharmacodynamic properties. Drug interaction is the major factor that might cause ADR, therapeutic failure and drug related harm to the patients, as drug interactions can effect patients' clinical outcome, quality of life as well as contribute to unnecessary health care costs.

In this study, $8 \%$ of ADRs were identified among all drug related problems, this percentage is lower than the percentage of $13.4 \%$ in study done by Rashed et al. ${ }^{12}$ The most common ADRS include hypersensitivity reactions like rashes and allergy due to antibiotics such as ceftraixone and amoxyclav (amoxicillin+ clavulanic acid). The second most common type of ADR was loose stools due to amoxyclav, vomiting due to ceftriaxone, ciprofloxacin and the rare adverse event like incidence of Redman's syndrome by wrong administration (faster infusion) of vancomycin were also reported. All the identified ADR's were reported to PVPI using CDSCO
ADR reporting form. Following the Adverse drug reaction, the next drug related problem is drug duplication identified in $3.03 \%$ of cases.

Out of 66 drug related problems identified, 8 (5.33\%) were rated as minor, 27 (74\%) were rated as moderate and 31 $(20.6 \%)$ were rated as major. This finding correlates with the observation carried out in the several studies in India where moderate significance of drug related problems were mostly observed followed by minor and major significance levels. Minor interventions are small adjustments and optimization to therapy, which are not expected to significantly alter the hospital stay, resource utilization and clinical outcome. Moderate interventions are which expected to enhance effectiveness of drug therapy producing minor reductions in patient morbidity or treatment costs. Major interventions are those which are expected to prevent or address very serious drug related problems with a minimum estimated effect on reducing hospital stay but not less than 24 hours.

Most of the recommendations made in this study were duration change $(34.66 \%)$ and drug change $(6.66 \%)$. Other recommendations include dose reduction (1.33\%), drug termination (4\%), which differs from study by Satish Kumar BP et al, where drug discontinue was reported as most common suggestion made. ${ }^{10}$ Duration change was done in drug interactions and drug change and dose reductions were done in cases of adverse drug reactions and duplication errors.

The acceptance rate of clinical pharmacist recommendation and change in drug therapy was found to be high. Among 66 recommendations, 57 (86.6\%) interventions were accepted and changed. However, in 9 $(13.33 \%)$ of total recommendations, the suggestions made by the clinical pharmacist was accepted but the therapy was not changed. This was because the suggestion provided was thought to be insignificant in contrast to patients' current severe clinical condition by the physicians or hesitated to change the prescription immediately without close monitoring of patients. Some percentage of suggestions were neither accepted nor changed. This finding is similar when compared with other studies of Klobschaver et al, and Viktill KK et al. ${ }^{13}$

Out of 66 interventions, interventions provided to nurse were $19(30 \%)$, to care taker were $32(48 \%)$ and to physicians were $14(22 \%)$.

\section{CONCLUSION}

Pediatrics are the most vulnerable group among the population of all the age groups and more prone to drug related Problems due to their underdeveloped pharmacokinetic and pharmacodynamic changes.

Present study concludes that the clinical pharmacist plays a major role in identifying, assessing and resolving the drug related problems and medication errors in pediatric 
department, thereby enhancing the therapeutic outcomes. Multiple regimens, medication errors, co morbidities and the patient's age are the major causes of DRPs.

Present study shows that suggestions provided by the clinical pharmacist are well accepted by the Physicians, Nurses, and other Healthcare professionals, thus collaborative work of both physician and clinical pharmacist improves patient health related quality of life.

In India the clinical pharmacy services are yet at the infancy stage, very few private hospitals were adopted the system in which clinical pharmacist provides the clinical pharmacy services, while this clinical services are totally scarce in government hospitals. So, government needs to improve the health care system by accepting the clinical pharmacy services thereby improving the healthy, professional relationship between the clinical pharmacist and the physician, nurses and other health care professionals reducing the drug related problems and other effects of the drugs.

\section{ACKNOWLEDGEMENTS}

Authors would like to express our gratitude to all the physicians and PGs of department of paediatrics, SVRRGG hospital for allowing us to perform our work and also for their support and cooperation.

Funding: No funding sources

Conflict of interest: None declared

Ethical approval: Not required

\section{REFERENCES}

1. Parthasarathy A ED. IAP Textbook of paediatrics $4^{\text {th }}$ ed.Newdelhi: Jaypee publishers 2009 Available at: https://www.jaypeedigital.com/Book/BookDetail?isb $\mathrm{n}=9788184485806$ (Accessed $9^{\text {th }}$ November 2017).

2. Kearns GL, Abdel-Rahman SM, Alander SW, Blowey DL, Leeder JS, Kauffman RE. Developmental pharmacology-drug disposition, action, and therapy in infants and children. N Eng J Med. 2003 Sep 18;349(12):1157-67.

3. Sanghera N, Chan PY, Khaki ZF, Planner C, Lee KK, Cranswick NE, et al. Interventions of hospital pharmacists in improving drug therapy in children. Drug Safety. 2006 Nov 1;29(11):1031-47.

4. Emerson technologies, delivering to improve health; 2010. Available at:
https://www.emersonecologics.com/Content/pdf/prac ticetools/Pediatric_Doses.pdf. Accessed $9^{\text {th }}$ August 2017.

5. Baena MI, Faus MJ, Fajardo PC, Luque FM, Andres Cabrera FJ, Antonio Zarzuelo FF. Medicine-related problems resulting in emergency department visits. Eur J Clin Pharmacol. 2006;62:387-93.

6. Blix HS, Viktil KK, Moger TA, Reikvam A. Characteristics of drug-related problems discussed by hospital pharmacists in multidisciplinary teams. Pharmacy World Sci. 2006 Jun 1;28(3):152.

7. Blix HS, Viktil KK, Reikvam $\AA$, Moger TA, Hjemaas BJ, Pretsch P, et al. The majority of hospitalised patients have drug-related problems: results from a prospective study in general hospitals. Eur J Clin Pharmacol. 2004 Nov 1;60(9):651-8.

8. Krahenbuhl-Melcher A, Schlienger R, Lampert M, Haschke M, Drewe J, Krahenbuhl S. Drug-related problems in hospitals: a review of the recent literature. Drug Saf. 2007;30(5):379-407.

9. Ragesh G. The Study on Assessment and Evaluation of Clinical Phrmacy Servises in Paediatric Inpatients in Tertiary Care Teaching Hospital. Int J Pharm Sci Rev Res. 2015;33(2):16-20.

10. Dahal PR, Venkataraman R, Fuloria PC. Assessment of clinical pharmacist intervention in tertiary care teaching hospital of Southern India. Asian J Pharmaceut Clin Res. 2013;6(2):258-61.

11. Jose B, Shareef J, Shenoy R. Assessment of drug related problems and pharmacist intervention in pediatric drug therapy in a tertiary care teaching hospital. Am J Pharm Tech Res. 2016;6(2):209-18.

12. Rashed AN, Neubert A, Tomlin S, Jackman J, Alhamdan H, AlShaikh A, et al. Epidemiology and potential associated risk factors of drug-related problems in hospitalised children in the United Kingdom and Saudi Arabia. Eur J Clin Pharmacol. 2012 Dec 1;68(12):1657-66.

13. Viktil KK, Blix HS. The impact of clinical pharmacists on drug-related problems and clinical outcomes. Basic Clin Pharmacol Toxico. 2008 Mar;102(3):275-80.

Cite this article as: Deepishka P, Gali SD, Arcot M, Durga Prasad TS. Assessment of drug related problems and clinical pharmacist interventions in paediatric department of a tertiary care teaching hospital. Int J Basic Clin Pharmacol 2018;7:1934-9. 